\title{
ATTAINING COST EFFICIENCY IN CONSTRUCTING SPORTS FACILITIES FOR BEIJING 2008 OLYMPIC GAMES BY USE OF OPERATIONS SIMULATION
}

\author{
Wah-Ho Chan, Ming Lu \\ Dept. of Civil and Structural Engineering \\ Hong Kong Polytechnic University \\ Hong Kong, CHINA
}

\author{
Jian-Ping Zhang \\ Dept. of Civil Engineering \\ Tsinghua University \\ Beijing, CHINA
}

\begin{abstract}
To maximize the cost efficiency in constructing the sports facilities for the Beijing 2008 Olympic Games, we applied the state-of-the-art construction operations simulation modeling to plan the operations of installing the steel structure, find the proper installation sequence and formulate the assembling area use schedule. The SDESA platform resulting from in-house research was utilized as the simulation tool for evaluating how the construction time for the steel structure of the "bird's nest" (the main stadium) would change subject to different steel installation sequences combined with varied schedules for assembling area use. The simulation outputs and the process animation - obtained from SDESA- not only validated the SDESA model, but also convinced the site management of the effectiveness of SDESA modeling and aided the site engineers in designing the optimum construction method.
\end{abstract}

\section{INTRODUCTION}

As "cost efficiency" was emphasized in preparing for the 2008 Beijing Olympic Games, the construction team was highly motivated to take advantage of new technologies and materials as well as innovative management practices to ensure the timely delivery of the sport facilities, while reducing cost and maintaining quality standards. The architectural design of the Beijing National Stadium structure bears resemblance to a bird's nest, hence the facility is nicknamed the "bird's nest". To maximize the cost efficiency in building the structure, we applied state-of-the-art construction operations simulation modeling to plan the operations of installing the complex steel structure, identify the proper installation sequence and formulate the assembling area use schedule.

The "bird's nest" is situated in the Olympic Park at the Northern part of Beijing and will host the opening and closing ceremonies of the 29th Olympics, as well as the track and field events. The grandstand is a huge bowl-shaped concrete structure, surrounded by a giant steel latticework that forms the saddle-shaped frame roof $(330 \mathrm{~m}$ long, $300 \mathrm{~m}$ width, height varied from $40 \mathrm{~m}$ to $69 \mathrm{~m}$ ), with an oval opening $(185 \mathrm{~m} \mathrm{x} \mathrm{128m)} \mathrm{at} \mathrm{the} \mathrm{centre.} \mathrm{The} \mathrm{frame} \mathrm{roof} \mathrm{is} \mathrm{sup-}$ ported by 24 steel columns circumventing the grandstand, as shown in Fig. 1. On completion, the "bird's nest" can accommodate up to 100,000 spectators and will become a landmark facility in Beijing.

The construction of large and complex structures demands more precise, sophisticated planning methods to deal with constraints associated with material, space, equipment and technology (Tommelein 1998). The construction operations are confined in a limited site space and present particular challenges on material management, which encompasses (1) organizing storage areas, (2) expediting and sequencing material deliveries, and (3) planning material processing and installation as it is delivered (Thomas et al. 1989). In the case of the "bird's nest" project, the production of the steel assembly units was well planned and their deliveries were timely, imposing no constraints to site operations planning. The challenges the site management faced were mainly (1) how to coordinate the concrete contractor's and the steel contractor's use of the limited assembly areas on site, (2) how to plan the installation sequence of columns and frames (roof trusses), and (3) how to optimize the utilization of limited crane resources.

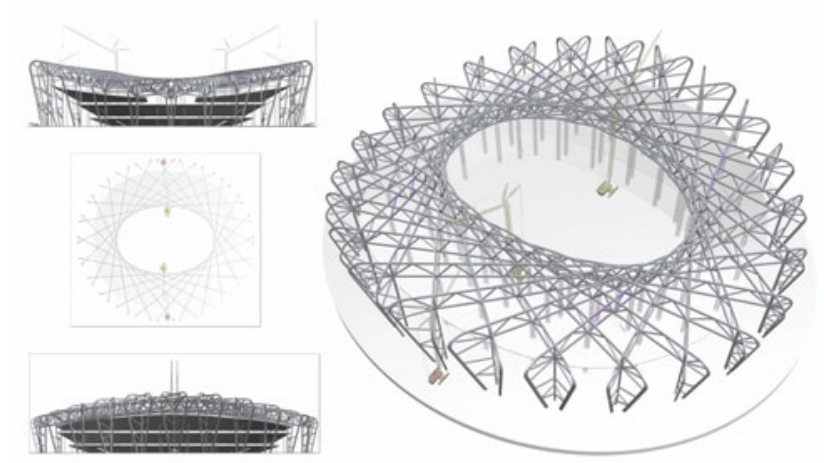

Figure 1: Steel structure of the "Bird's Nest" 
The Simplified Discrete-Event Simulation Approach (SDESA) has been developed at Hong Kong Polytechnic University in the past five years with the intention of providing construction engineers with a straightforward simulation tool for describing, evaluating, and improving construction methods (Lu 2003). The potential of applying SDESA in the improvement of material delivery logistics has been demonstrated in several previous studies, including (1) planning the delivery and storage of precast girders in viaduct construction (Chan and $\mathrm{Lu} 2005$ ), (2) optimizing the schedule for dispatching limited mixer trucks and delivering ready-mixed concrete to building sites ( $\mathrm{Lu}$ and Lam 2005). Lu and Wong (2005) compared the SDESA methodology with the PROMODEL - which is influential and popular in manufacturing. This comparison verified the SDESA computer platform (an in house development) by applying PROMODEL alongside SDESA to typical construction systems and found SDESA to be more flexible and straightforward in modeling construction systems. In this paper, the SDESA platform is utilized as the simulation tool for evaluating the construction time as needed for installing the steel structure of the "bird's nest" subject to different steel installation sequences combined with varied schedules for assembling area use.

\section{PROBLEM STATEMENT AND CONSTRUCTION METHOD}

The large span and irregular layout of the steel latticework of the "bird's nest" required the use of the most advanced alloy steel featuring high-strength, light-weight, while also providing good weldability. The structural steel was supplied by three steel mills across China, hauled by long trucks to the construction site, and then pieced together into subassemblies of columns and frames in the assembling areas on site. Each subassembly (a column or a frame) was then lifted by a heavy-duty crane to its designated location for installation. Upon careful position calibration, the subassembly was welded to form part of the steel structure. The heavy-duty crane was then released to lift another subassembly according to the detailed job planning. It is important to note that the heavy-duty cranes employed for steel installation were expensive and limited in availability (i.e. two 600-ton crawler cranes \& two 800ton crawler cranes), and the cranes were the leading and critical resource in the construction operations.

For the ease of management, the steel contractor divided the installation of the whole steel latticework into North and South sections (Fig. 2), which were further separated into inner and outer rings. Two 800-ton crawler cranes would be available for the steel installation of the outer ring, one serving the North section while the other being allocated to the South section. Similarly, two 600-ton crawler cranes would be committed for the inner ring construction. The outer ring installation, made up of 24 steel columns and 86 steel frames, was selected for an intensive study in this re- search, as the construction operations required longer duration and involved more complicated procedures.

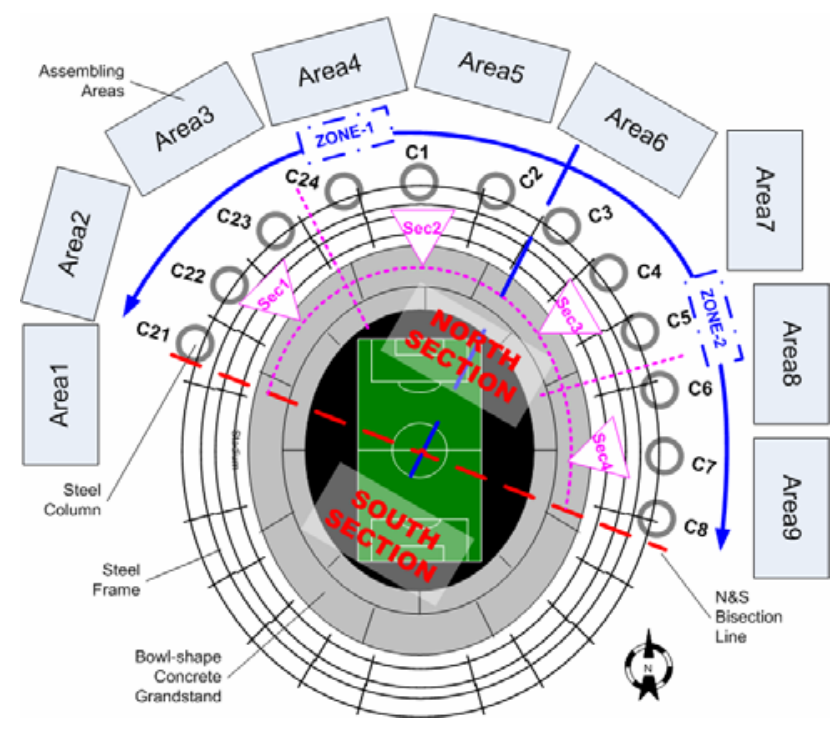

Figure 2: Site layout plan

To shorten the total construction period, the steel structure installation of the outer ring was planned to start when the concrete work of the grandstand neared completion. That meant that part of the steel structure work would be running concurrently with the concrete work for a period of transition time, within which, resources required for the steel work increased gradually while the resources needed by the concrete work tapered off. Site space was the crucial resource required by both steel and concrete crews. Intuitively, the site managers anticipated that the provision of additional resources to accelerate the concrete activities would release site space at an earlier time for steel assembling, potentially contributing to the earlier completion of the steel structure. However, the complexities and interactions on site made it difficult for site engineers to ascertain whether the overall savings in steel installation time would outweigh the added cost of crashing the concrete work on the grandstand.

Another uncertain issue for the steel structure installation was how to sequence the installation of subassemblies. Because of the irregular shape of the structure, each subassembly was unique in dimension and structural complexity, requiring different time duration for assembly and installation. In combination with the provision schedules of assembly areas and the limited number of cranes, different sequences for installing the steel structure might result in changes in the total steel installation duration.

In this research, we applied the state-of-the-art construction operations simulation to model the complicated steel structure construction of the "bird's nest", and evaluated the response of the total duration in postulated scenarios, considering various steel component assembling sequences and assembly area provision schedules. 


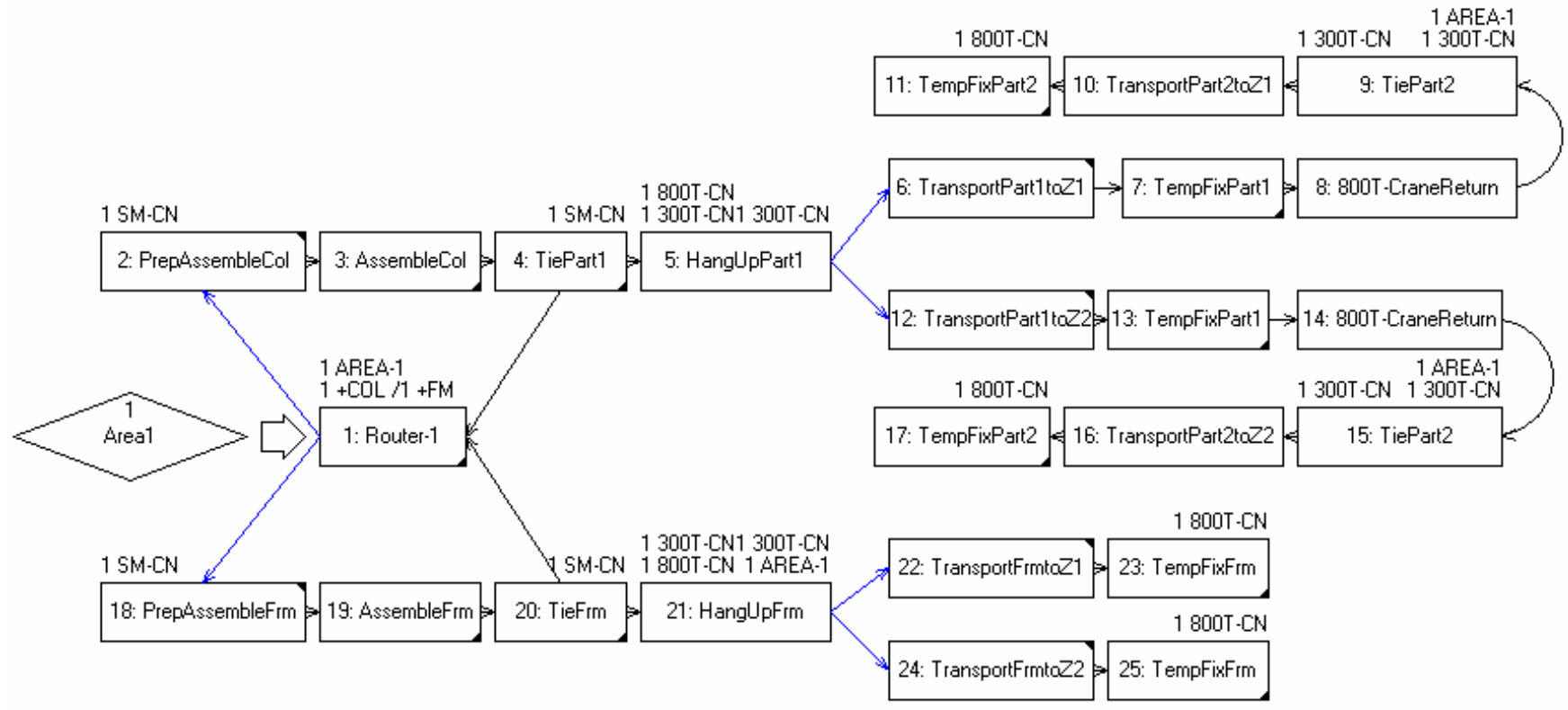

Figure 3: Work flow for assembly area-1 of the SDESA model

\section{SIMULATION MODEL}

Information obtained from site contractors in September 2005 provided the input data to simulation modeling, including the proposed construction methods, a CPM construction schedule, and the site layout plan. We only modeled the installation of the steel structure of the outer ring in the North section, since activities in the North and South sections were relatively independent in terms of work space and crane resources and could be carried out simultaneously. Because the steel installation crews worked in shifts and round-the-clock, it was not necessary to consider the breaks or holidays in the simulation model.

As shown in Fig. 2, a total of nine assembly area blocks were involved in the simulation model. Hence, nine work flows, one around each assembly area block, made up the whole SDESA simulation model. Fig. 3 shows the sub-model for Area 1, in which the area block is treated as a reusable resource entity, initiated at a diamond node at the time when the area block was available to handle the steel installation. In SDESA, an activity starts when its predecessors are completed and the required resources are all available. Resources required by an activity are marked at the top left corner of the activity block, while resources released at the end of an activity are marked at the top right corner. For instance, a small crane (1 SM-CN) was required for handling a column in assembling (from activity block "2. PrepareAssembleCol", "3. AssembleCol" to "4. TiePart1"), and a 300-ton hydraulic crane was needed to help turn over and hold up the lower part of the column when it was being lifted by an 800 -ton crawler crane (Activity block "5. HangUpPart1").
The activity "Router" (the rectangular node after the diamond node in Fig. 3) would obtain either a column or a frame from the resource pool, i.e. " $+\mathrm{Col} /+$ Frm". Note the prefix "+" denoting Disposable Resource (DR) entities in SDESA (such as material or information units); disposable resources are organized in the resource pool together with non-disposable ones (such as manpower and machinery resources). Each "+Col / +Frm" DR entity carries five attributes, as shown in Table 1, for defining the corresponding subassembly it denotes. The "Router" activity also acts as a decision node: if the DR entity being processed is column (Attribute 2 equal to 0 ), then it will be channeled through the upper branch into the column installation activities; otherwise the simulation entity is directed to the lower branch for undergoing the frame-installation activities (Fig. 3 ). Note the arrows linking activities " 4 . TiePart1" and "20. TieFrm" to the "Router" will direct a simulation entity into "Router" upon completion of the "tie column or frame" activities (activities 4 or 20 in Fig. 3), meaning the area block is released and ready to assemble the next job. According to the method statement obtained from the steel contractor, the installation of a column entailed placing the upper and lower portions of the column in two consecutive steps, while a frame was placed in one step. Therefore, the upper workflow in Fig. 3 contains two rounds of column installation by use of a $300 \mathrm{~T}$ crane and an $800 \mathrm{~T}$ crane. Note the branching after the activity node " 5 . HangUpPart1" is to direct the column being handled to the correct installation zone (either Zone 1 or Zone 2 according to the "Installation destination zone" attribute of a DR entity representing a subassembly). 
Table 1: Attributes of column or frame disposable resource

\begin{tabular}{|l|l|}
\hline \multicolumn{1}{|c|}{ Attribute } & \multicolumn{1}{c|}{ Meaning and Function } \\
\hline $\begin{array}{l}\text { Subassembly } \\
\text { reference code }\end{array}$ & $\begin{array}{l}\text { A short ID code of the steel com- } \\
\text { ponent }\end{array}$ \\
\hline Column or Frame & 0 for a Frame and 1 for a Column \\
\hline $\begin{array}{l}\text { Structural } \\
\text { complexity index }\end{array}$ & $\begin{array}{l}\text { A real number reflecting the work } \\
\text { content and complexity of subas- } \\
\text { sembly, used for adjusting assem- } \\
\text { bling and installation duration in } \\
\text { simulation }\end{array}$ \\
\hline $\begin{array}{l}\text { Installation } \\
\text { destination zone }\end{array}$ & $\begin{array}{l}\text { 1 or 2 representing the installation } \\
\text { zone situated at the West and the } \\
\text { East of the site respectively (Fig. } \\
\text { 2) }\end{array}$ \\
\hline $\begin{array}{l}\text { Installation } \\
\text { sequence index }\end{array}$ & $\begin{array}{l}\text { Sequential numbers that control } \\
\text { the order of subassembly installa- } \\
\text { tion; the smaller value, the higher } \\
\text { priority for processing in simula- } \\
\text { tion }\end{array}$ \\
\hline
\end{tabular}

The slow moving speed of the crane caused considerable transit time to elapse when the crane moved from an assembly area to an installation zone (as modeled with "TransportPart1ToZ1" activity). On the other hand, when an 800-ton crane finished the task at the installation zone (i.e. released from the last activity "TempFixPart2" in the work flow), it would travel back to the earliest-ready assembly area to lift the next subassembly as controlled by the "installation sequence index" attribute of the subassembly entities. As the crane was likely to move to a different assembly area (e.g. Area 2 instead of Area 1 in Fig. 3 ), the transit duration from two installation zones (Zone 1 or 2) to various assembly areas was specified in the centralized "Resource Transit Information System" of the SDESA model. As such, adding extra transit activities and linking arrows was avoided and the simplicity of the model representation was maintained.

Table 2 summarizes the activity duration entered into the SDESA model. Because the model was setup before the construction, the activity duration was given in constant values in terms of working days estimated by the site engineers and the construction planners. The duration of the assembly and installation activities is defined as a linear function of the subassembly's attribute "Structural Complexity Index" in order to distinguish the work content and complexity of each subassembly. In addition, the duration required for the movement of the 800-ton crane was specified as the travel distance divided by the crane's moving speed (i.e. one attribute of the 800 T-crane resource entity). Note that the travel distance was approximated as the shortest distance between the start location and the finish location, which was automatically determined by the SDESA site layout module based on the coordinate data of key site locations.
Table 2: Activity duration summary

\begin{tabular}{|c|c|}
\hline Activity & Duration (Day) \\
\hline Router & 0 \\
\hline $\begin{array}{l}\text { PrepAssemble- } \\
\text { Col/Frm }\end{array}$ & 2 \\
\hline AssembleCol/Frm & $\begin{array}{l}10+2.8 \times \text { Structural Complexity } \\
\text { Index (For Column Assemble) } \\
7+3.5 \times \text { Structural Complexity In- } \\
\text { dex (For Frame Assemble) }\end{array}$ \\
\hline TiePart/ Frm & 0.5 \\
\hline HangUpPart/ Frm & 0.5 \\
\hline $\begin{array}{l}\text { TransportPart/ } \\
\text { Frm }\end{array}$ & Dist / 800t_Crane_Speed \\
\hline TempFixPart/ Frm & $\begin{array}{l}2.5+0.5 \times \text { Structural Complexity } \\
\text { Index (For Column Installation) } \\
1.2+0.8 \times \text { Structural Complexity } \\
\text { Index (For Frame Installation) }\end{array}$ \\
\hline 800T-CraneReturn & ( Dist / 800t_Crane Speed )/ 2 \\
\hline
\end{tabular}

\section{MODEL VALIDATION}

Although the methodology and the computer platform of SDESA had been thoroughly tested and verified in comparison with two established simulation packages -CYCLONE (Lu and Chan 2004; Lu 2005) and ProModel (Lu and Wong 2005), the modeling complexity of the case being addressed deserves careful model validations. As the model was set up to represent construction operations during the planning period of the actual project and the contractor had not previously experienced similar operations on past projects, it was infeasible to collect actual operations data from the real world for model verification and validation purposes. Instead, the validation of the simulation model resorted to: (1) the tracing of the simulation results in detail, (2) the comparison of the simulation outputs against the engineer's estimates, and (3) visualization of the simulated operations through animation.

Prior to looking into the complete simulation model, the submodel (as shown in Fig. 3) was examined to ensure the SDESA was able to execute the complex construction operations as designed. Only four subassemblies (namely, two columns and two truss frames) were considered in the validation testing to undergo the assembling and installation procedures; two subassemblies (one column and one frame) would be installed in Zone 1 and the other two in Zone 2, respectively. Then, by executing the SDESA model, the activity sequence along with the activity duration was traced. Fig. 4 shows a glimpse of the tracing record of one column subassembly, which was set to be installed at Zone 1 . The activity sequence, as interpreted from the tracing record, followed the correct column installation procedure that had occurred at the right locations; for instance, the upper part of the column was installed after the completion of its lower part. Activity durations were also obtained from the tracing record by deriving the dif- 
ference between the End Time and the Begin Time of each activity. Because the column subassembly of concern had its Structural Complexity Index set as 4, the assembling duration and the temporary installation duration were expected to be 21.2 days and 4.5 days, respectively, according to the formulas for determining the durations of these two activities (given in Table 2). The corresponding activity durations derived from the tracing record of the SDESA simulation (Fig. 4) equated with the expected values. Thus, the model was found to be a valid representation of the construction operations being designed.

The above submodel for site area 1 was then readily expanded to generate the complete model for the entire site operations. The simulation model was executed and the system outputs (such as the total construction duration of the steel structure) were collected. The simulated total duration for the base case was 307 days, which was close to the 300 days estimated by site engineers using the conventional CPM (MS Project). An investigation of the CPM schedule prepared by the site engineers revealed the difficulty and inadequacy of using CPM to address resource availability constraints, space scheduling and site layout planning, dynamic work flows, and repetitive units of construction. To be more specific, in the CPM schedule, (1) the limited assembly areas were not factored in; (2) the constraint of multiple subassemblies sharing one heavyduty crane in installation was neglected; and (3) the duration incurred in the transit of the heavy-duty cranes was ignored. In addition, the CPM schedule in the form of a network diagram or a bar chart appeared cumbersome in size when dealing with a large number of installation units which required repetitive operations yet featured peculiar characteristics. As a result, it was difficult to read and communicate the construction plan, and furthermore, it was inflexible to accommodate any changes to the construction scheme in devising and evaluating alternative construction schemes. In particular, the site engineers emphasized the space scheduling need but they had no idea on how to put the constraint of the limited assembling areas into the CPM model. As a result, they simply assumed site space would be sufficient and all subassemblies would be well assembled just in time for installation.

The presentation of the simulation outputs by animation was also conducive to model validation, which replayed the steel structure construction operations being simulated. A series of animation snapshots were captured in Fig. 5 for illustrating the work flows of installing two subassemblies in the simulated construction operations. The assembling and installation processes of two roof frame subassemblies included five tasks: (1) material transportation, (2) assembling the subassembly, (3) transportation of the subassembly, (4) installation of the subassembly, and (5) return of the crane.

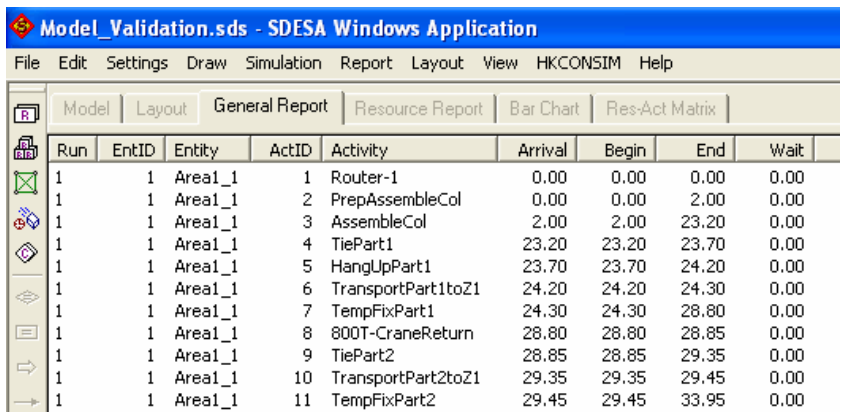

Figure 4: Tracing record collected from the submodel validation test

The snapshot \#1 in Fig. 5 shows the key locations predefined in the model (circles tagged with location descriptions). The colored line sections connecting these key locations represent the transit activities (e.g. the transportation of a subassembly from one location to another) and the colored square blocks situated at these key locations represent the production activities (e.g. assembling columns in an assembling area) (Lu et al. 2003). When the associated activity is being executed during animation the corresponding lines or blocks will be highlighted. These locations were then linked to the activities defined in the SDESA simulation model so as to enable the animation of simulations. At the beginning of the operations, the steel elements were transported from the site storage area to the assembly areas (i.e. Area $4 \& 5$ in \#2). The truss icons represent the steel elements while the colored circular dots represent the resources involved in facilitating the related activities. Upon arrival of the steel elements, they were assembled in the assembling areas (\#3). After the assembling, the subassembly (the truss icon) was lifted by the 800 -ton crane (the yellow circular dot) to the designated installation location (i.e. Zone 1 in \#4). Once the crane had finished the installation of the subassembly at Zone $1(\# 5)$, it then returned to the assembly area where the other subassembly was ready for installation. The solid yellow circular dot - representing the crane- changed into a donut icon to denote the nonengagement state when it was moving back for handling another subassembly.

The animation for the whole simulated operations system features higher order of complexity and scale, involving more locations, activities, and movements of icons and dots. Fig. 6 gives a snapshot of the animation for the entire operations simulation. After watching the animation, the site engineers obtained a more clear understanding on the model and conceded that the operations simulated was consistent with what they had proposed. 


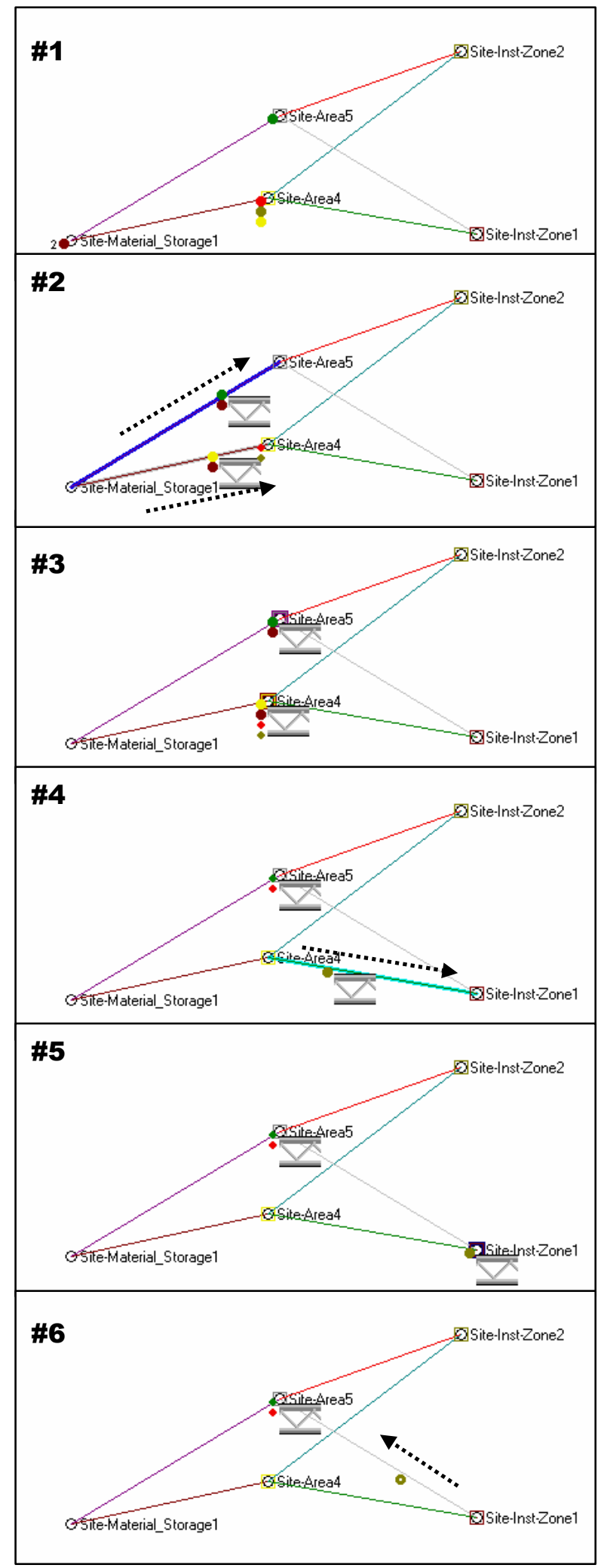

Figure 5: Screen snapshot series showing the operations process of installing two subassemblies

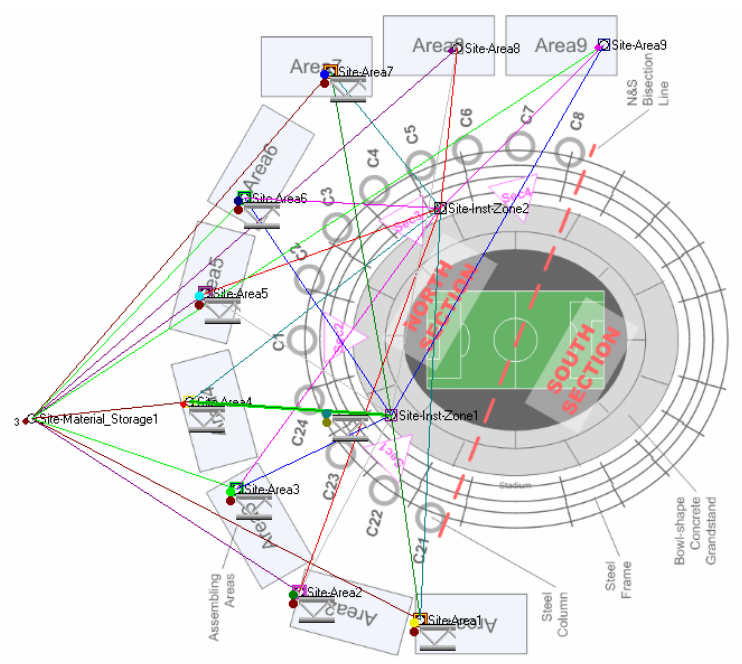

Figure 6: Screenshot of the SDESA model animation

In brief, the simulation result and the process animation for the base case scenario validated the SDESA model, convincing the site management of the effectiveness of SDESA modeling. Next, in collaboration with the site managers, we designed a series of simulation experiments aimed to assess how the total duration would change under various assembly sequences and assembly area provision schedules.

\section{SIMULATION EXPERIMENTS}

As shown in Fig. 2, the steel assembly and installation sequence could follow three possible directions, namely (1) the clockwise direction (starting from the Column 21 to the Column 8), (2) the counterclockwise direction (starting from the Column 8 to the Column 21), and (3) an ascending order by column height (installing Column 1 then Column 2 then Column 24 ...until Column 21 then construct Column $6-8$, as shown in Fig.7). Besides the direction of work, two construction schemes were also considered in designing the installation sequences. The first scheme was to erect all the columns first, followed by the installation of the frames. The second scheme was to build sector by sector, each being a grouping of three neighboring columns and their associated frames (Fig. 2 and 3).

Six construction sequences were postulated (Table 3), each combining an option of work direction with an option of construction scheme. For instance, the "Clockwise Column then Frame" sequence means all columns would be built in clockwise direction; following the installation of the last column, all the frames would then be installed in clockwise direction as well. Note site engineers proposed the last construction sequence ("EngSugg."), by which the steel structure would be built sector by sector, moving from the sector with the shortest columns to the sector with the tallest column (as shown in Fig. 7). 
Surrounding the stadium, 18 assembly areas ( 9 for the North half and 9 for the South half) would be provided for preparing subassemblies. Note not all of them could be made available for the steel contractor, in that as the steel construction started some of the assembly areas were still occupied by the concreting contractor for the grandstand construction. According to the site plan (the base case), Areas 4, 5 and 6 would be available upon the start of the steel structure installation; 50 days later, Areas 1, 2, 3 and 7 would be ready; and Areas 8 and 9 would be open 100 days later. Two more assembly area provision schedules were proposed as given in Table 4. The "crash" case was to accelerate the concrete construction so the areas occupied by the concrete contractor would be released earlier; the "alternative" case was to swap the available times of the assembly areas in the base case, making Areas 1,2 and 3 available at day 0 while releasing Areas 4, 5,6 and 7 at day 50 .

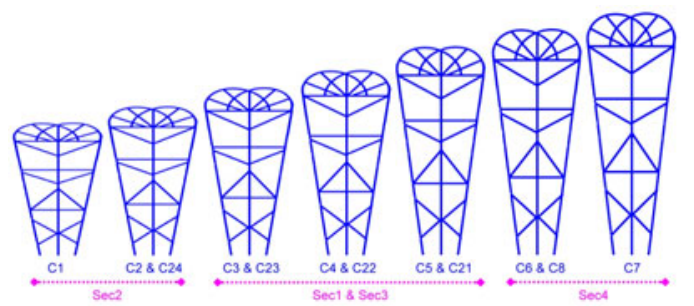

Figure 7: Profile illustration of the columns and sectors in the north section

Table 3: Descriptions of Proposed Assembling Sequences

\begin{tabular}{|l|c|}
\hline \multicolumn{1}{|c|}{ Assembling Sequence Name } & Code \\
\hline Clockwise Column then Frame & CW-Col \\
\hline Counterclockwise Column then Frame & CtrCW-Col \\
\hline Symmetrical Column then Frame & Sym-Col \\
\hline Clockwise 3 Sector by Sector & CW-Sect \\
\hline Counterclockwise 3 Sector by Sector & CtrCW-Sect \\
\hline Site Engineers' Suggestion (BC) & EngSugg. \\
\hline
\end{tabular}

Table 4: Start-open date of different assembling area provision schedules

\begin{tabular}{|c|c|c|c|}
\hline & Base & Crash & Alternative \\
\hline Area-1 & 50 & 36 & 0 \\
\hline Area-2 & 50 & 36 & 0 \\
\hline Area-3 & 50 & 36 & 0 \\
\hline Area-4 & 0 & 0 & 50 \\
\hline Area-5 & 0 & 0 & 50 \\
\hline Area-6 & 0 & 0 & 50 \\
\hline Area-7 & 50 & 36 & 50 \\
\hline Area-8 & 100 & 82 & 100 \\
\hline Area-9 & 100 & 82 & 100 \\
\hline
\end{tabular}

\section{SIMULATION RESULTS}

Table 5 summarizes the simulation results in terms of the total installation time under various combinations of as- sembly area provision schedules and steel installation sequences.

Table 5: Summary of the simulation results

\begin{tabular}{|c|c|c|c|}
\hline & Base & Crash & Alternative \\
\hline CW-Col & 310 & 310 & 303 \\
\hline CtrCW-Col & 316 & 316 & 307 \\
\hline CW-Sect & 310 & 310 & 303 \\
\hline CtrCW-Sect & 315 & 316 & 306 \\
\hline SymCol & 307 & 308 & 302 \\
\hline Eng-Sugg. & 308 & 307 & 302 \\
\hline
\end{tabular}

It was observed that advancing the available time for assembly areas (as from the "base" case to the "crash" case) would not shorten the total installation time, regardless of the installation sequence. This indicated that there was no need to speed up (or crash) the concrete grandstand construction work. On the other hand, swapping available time of assembling areas in the base case (contrasting the "base" case with the "alternative" case) would help shorten the total installation time by 3-10 days under different installation sequences. Across the columns in Table 5, the total installation time was found to be not sensitive to varied installation sequences. Only the two counterclockwise options were about 6-8 days longer than the others in the "base" case and the "crash" case; and the different sequence options resulted in comparable performances (302306 days) in the "alternative" case. Thus, the optimum scenario was decided as the combination of the "EngSugg" installation sequence and the alternative case for assembly area provision schedule, i.e. to build the steel structure sector by sector from the sector with the shorter columns to the sector with the taller columns and, at the same time, only to swap the available time of assembling areas in the base case, without the need of accelerating concrete construction.

\section{CONCLUSIONS}

The challenges faced by the site management in building the "bird's nest" project were mainly: (1) how to coordinate the concrete and the steel contractors in the use of limited assembly areas on site, (2) how to design the installation sequence of columns and frames (roof trusses), and (3) how to optimize the utilization of limited crane resources. Existing project planning methodologies, such as the CPM, were found to be inadequate in providing decision support for the site engineers. In collaboration with the steel contractor of the "bird's nest" project, we applied the state-ofthe-art construction operations simulation to model the complicated steel structure construction, and evaluated the response of the total duration under a number of postulated scenarios considering various steel component assembly sequences and assembly area provision schedules. 
The Simplified Discrete-Event Simulation Approach (SDESA) has been developed at Hong Kong Polytechnic University over the past five years with the intention of providing construction engineers with a straightforward simulation tool for describing, evaluating, and improving construction methods. In this research, the SDESA platform provided the simulation tool to facilitate the development of a complex construction operations simulation. The simulation result along with the process animation not only validated the SDESA model, but also convinced the site management of the effectiveness of SDESA modeling and aided site engineers in selecting the optimum construction method.

\section{ACKNOWLEDGMENTS}

The research presented in this paper has been substantially supported by Hong Kong Research Grants Council (Project A/C B-Q580 PolyU5049/02E). The writers also acknowledge Mr. Gao Shu Dong of Beijing Urban Construction Group Co. Ltd. for facilitating the research.

\section{REFERENCES}

Chan, W. H. and Lu, M. (2005) "Logistics and operations simulation in precast viaduct construction: case study", Proceedings of the 2005 ASCE International Conference on Computing in Civil Engineering, Cancun, Paper No. 131, ASCE.org/publication online library.

Lu, M. (2003). "Simplified discrete-event simulation approach for construction simulation", Journal of Constuction Engineering Management, ASCE, 129(5), pp 537-546.

Lu, M., Cao, M., and Zhang, J.P. (2003) "Synchronize operations planning and site layout planning by augmenting the simplified discrete-event simulation approach (SDESA)", Proceedings of Second International Conference on Construction in the 21st Century: Sustainability and Innovation in Management and Technology, pp 573-580 10-12 Dec. 2003, Hong Kong.

Lu, M., and Chan, W.H. (2004) "Modeling concurrent operational delays in construction activities with simplified discrete event simulation approach", the Proceedings of Winter Simulation Conference 2004, pp 12601267, Washington D.C., Dec, 2004.

Lu, M. (2005) "Adapted process-interaction modeling paradigm for construction simulation", Proceedings of the 2005 ASCE International Conference on Computing in Civil Engineering, 10 pages in CD, Cancun, Mexico, July, 2005.
Lu, M. and Lam, H. C. (2005). "Optimized concrete delivery scheduling using combined simulation and genetic algorithms", Proceedings of the 2005 Winter Simulation Conference, 2572-2580.

Lu, M., and Wong, L. C. (2005). "Comparing ProModel and SDESA in modeling construction operations". Proceedings of the 2005 Winter Simulation Conference., 1524-1532

Tommelein, I. (1998). "Pull-driven scheduling for pipespool installation: Simulation of a lean construction technique", Journal of Construction Engineering Management, ASCE, 124(4), pp 279-288.

Thomas, H. R., Sanvido, V. E., and Sanders, S. R. (1989). "Impact of material management on productivity - a case study", Journal of Construction Engineering Management., ASCE, 115(3), pp 370-384.

\section{AUTHOR BIOGRAPHIES}

WAH-HO CHAN received a civil and structural engineering bachelor degree from the Hong Kong Polytechnic University in 2002, and is now an MPhil. candidate of the Department of Civil and Structural Engineering of the Hong Kong Polytechnic University. His research interest is around construction engineering and management, in particular, looking into current construction practices and making improvement on them through computer-modeling and IT application. He participated in an optimized resource scheduling project and is actively involved in an ongoing research project on construction operations/logistics simulation.

MING LU is Assistant Professor of Construction Engineering \& Management of the Department of Civil and Structural Engineering, the Hong Kong Polytechnic University. He received a Ph.D. degree from the University of Alberta, Canada. His research interest is development of easy-to-apply, cost-effective methodologies of artificial intelligence and computer simulations for construction engineering and project management. Dr Lu proposed the Simplified Discrete-Event Simulation Approach (SDESA) for construction simulation and has led the research effort of developing the SDESA computer platform. His email address is <cemlu@polyu. edu.hk>.

JIAN-PING ZHANG is a Professor of the Department of Civil Engineering, Tsinghua University, Beijing, China. She received a Ph.D. degree from the Hong Kong Polytechnic University, with research interests in 4D CAD, visualization, and construction planning. 